\title{
Effect of Eggplant Skin in the Process of Apoptosis in Cancer Cells
}

AUTHORS: Hoda Seraj, Fatemeh Afshari, Zahra Sadat Hashemi, Marzieh Timajchi, Ensieh Olamafar, Ladan Ghotbi SCHOOL: Rahe Shayestegan High School, Tehran/Iran

Editor's note: This project was a submission at the 2016 ICYS event, through the Araian Young Innovative Minds Institute, AYIMI, where Seraj was awarded a Bronze medal.

\section{Abstract}

The process of programmed and physiological cell death, or apoptosis, is generally characterized by distinct morphological characteristics and energy-dependent biochemical mechanisms. Apoptosis normally removes old, damaged, excessive and harmful cells and is essential for tissue homeostasis. Cancer is a disease in which damaged cells do go through apoptosis and ultimately uncontrolled cell division results in the formation of a malignant tumor. Stomach cancer is the most common cancer in Iran with about 7751 affected in the year of 1387 . This is about $10.17 \%$ of the total male and female population per year. Unfortunately, existing treatment options are often aggressive with harmful side effects for the patient. In this study, we decided to prepare anti-cancer drugs from natural ingredients such as eggplant skin which is rich in antioxidants. The primary hypothesis of this study was that due to the presence of compounds containing antioxidants in eggplant skin, the extract should be able to destroy cancer cells by activating their apoptosis. This hypothesis was examined by MTT colorimetric method in two series of cells: gastric cancer cells (AGS) and normal fibroblasts cells (FIB). The yellow MTT salt becomes an insoluble purple formazan by dehydrogenase enzymes in the active mitochondria of cells. The results of this study show that eggplant skin extracts in concentrations of $2.5 \mu \mathrm{M}$ have a high cytotoxic effect on gastric cancer cell lines, which could be due to the induction of apoptosis in these cells and the least effect on normal fibroblasts cells. Therefore, eggplant skin extract has a positive effect on the apoptosis of cancer cells and can be used in the production of stomach cancer drugs.

\section{Key Words}

Apoptosis, Cancer, Eggplant Skin, MTT Colorimetric Method

\section{Introduction}

Cancer (also called malignancy) is the growth of abnormal cells in the body. These extra cells grow together and form masses called tumors. There are more than 100 types of cancer, including breast, skin, lung, colon, prostate, and lymphoma cancers. Symptoms vary depending on the type. Cancer treatment may include chemotherapy, radiation, and/or surgery. Cancers are dependent on factors such as age, genetic background and gender. To transform a normal cell into a cancer cell, six changes are essential. Each of these changes cause the proliferation and spread of tumors: the presence of too many messages of growth, insensitivity to growth-inhibitor messages, apoptosis resistance, unlimited growth and proliferation, the ability of angiogenic and invasion to tissues, and metastasis power. The concept of apoptosis has been explicitly described many years previously [1]. Apoptosis occurs normally during development, in aging, and as a homeostatic mechanism to maintain cell populations in tissues. Apoptosis also occurs as a defence mechanism in immune reactions or when cells are damaged by disease or noxious agents [2]. There are a wide variety of stimuli and conditions, both physiological and pathological, that can trigger apoptosis. However, not all cells will necessarily die in response to the same stimulus. Irradiation or drugs used for cancer chemotherapy results in DNA damage in some cells, which can lead to apoptotic death through a p53-dependent pathway. Some hormones, such as corticosteroids, may lead to apoptotic death in some cells (e.g., thymocytes), while other cells are unaffected or even stimulated. There is also the issue of distinguishing apoptosis from necrosis; two processes that can occur independently, sequentially, as well as simultaneously [3,4]. In some cases, it's the type of stimuli and/or the degree of stimuli that determines if cells die by apoptosis or necrosis. Finally, apoptosis is a coordinated and often energy-dependent process. It involves the activation of a group of cysteine proteases called "caspases" and a complex cascade of events that link the initiating stimuli to the final demise of the cell. Apoptosis is the chromatin condensation along the nuclear membrane, shrinkage of the cell membrane, and finally fragmentation to the cell's apoptotic bodies. During the early process of apoptosis, cell shrinkage and pyknosis are visible by light microscopy [5]. With cell shrinkage, the cells are smaller in size, the cytoplasm is dense and the organelles are more tightly packed. Pyknosis is the result of chromatin condensation and this is the most characteristic feature of apoptosis [6] 
Gastric cancer is the fourth most common cancer worldwide and is considered one of the deadliest cancers. It is caused by both environmental and hereditary factors. Factors such as food habits, physical activity and smoking play very important roles in the development of this cancer. Chemotherapy is one of the cancer treatment methods, but the lack of selective cytotoxicity often causes intolerable side effects. The medicinal properties of plants in the treatment of various diseases were discovered in ancient times. More anti-cancer compounds are used today to treat cancer, which are derived from plants which have fewer side effects. Additionally, studies show that the consumption of fruits \& vegetables reduces cancer. In Iran, researchers have done several experiments on some cancers. N. Moheghy \& et al., 1390, investigated the cytotoxic effect of an aqueous extract of fresh ginger on breast cancer cells and found that the in a dilution factor of $1.150,50 \%$ of cells were apoptotic [7]. Similarly, M. Shokrzadeh \& et al., 1391, investigated the cytotoxic effect of Lagenaria siceraria extract on lung cancer cell lines (A549) and found that this extract has a significant inhibitory effect on lung cancer cells [8].

In this study, we were looking for a new material with high antioxidant properties, which will lead to the premature death of cancer cells, with minimal effect on healthy cells. We found that eggplant skin is high in antioxidants and makes cells resistant to premature aging. Our goal was to induce apoptosis in cancer cells by using antioxidants in eggplant skin. Our assumption was that the alcohol of the eggplant skin extract can induce apoptosis of stomach cancer cells (AGS).

\section{Cancers Causes and Treatment Methods}

Cancer is the growth and spread of abnormal cells in the body. The human body is composed of trillions of cells which together make tissues such as muscles, bones and skin. Most normal cells will grow, reproduce, and eventually die based on signals from inside or outside the body. If this process is balanced and happens orderly, the body remains healthy and retains its normal function. But the problem begins when normal cells undergo a "jump" or change and become cancer cells. With no apparent reason a normal cell may change to a cancer cell, but in most cases, frequent exposure to carcinogens such as alcohol and tobacco cause this. The behaviour and appearance of cancer cells differ from normal cells. DNA is responsible for controlling the shape and function of the cell. However, once the DNA is changed through mutations, the cell differs from a healthy cell nearby and cannot perform its natural work. The abnormal cell may then divide into two, then four, then eight, and so on. Many abnormal cells then develop from the original abnormal cell. These cells do not know when to stop multiplying. A group of abnormal cells may then form. If these cells continue to multiply, a large clump of abnormal cells, called a tumour, will form. Tumours may form in various parts of the body. Benign tumours grow slowly, and do not spread or invade other tissues. They are not cancerous and are usually not life-threatening. They often do no harm if they are left alone. However, some benign tumours can cause problems. For example, some grow quite large and may cause local pressure symptoms, or affect one's physical appearance. Also, some benign tumours that arise from in hormone glands can cause the gland to overproduce hormones, which can cause unwanted effects [9].

A malignant tumor is a second kind of cancerous tumor. The growth and dissemination of a malignant tumor will attack healthy tissues in the body. This compromises the reception of nutrients and oxygen by these healthy tissues and may lead to their death. Damaging of DNA or the material manufacturers of genes located in the cell nucleus cause cancer. In most cases, the cells can repair damaged DNA, but cancer cells do not have this ability. Individuals who inherit these damaged genes from their parents are more at risk than others for hereditary cancer. However, individuals can have an increased risk due to environmental factors such as genetic, virus, age, hot food and liquid intake, obesity, excessive consumption of meat and dairy products, geographic area, preservatives found in some foods, harmful radiation such as ultraviolet, $X$-rays or chemicals materials through food, drinks and air.

Treatment plans depends mainly on the type and stage of the cancer. The age and general health of the patient are also considered by physicians. The goal of treatment is often complete remission of cancer; otherwise, it is to control the disease and reduce symptoms as much as possible. Depending on the progression of the disease the initial plan may change. In some types of cancer, only one treatment gives the best results but for others it may be a combination of several methods of treatment. In general treatment procedures may be performed in one of the following forms:

1- Topical treatment: only in certain parts of the body, including: a) Surgery and b) Radiotherapy

2- Systemic therapy: effects the entire body, including: a) chemotherapy, b) biological and c) hormone therapy.

\section{Gastric Cancer}

Cancer is the third cause of death in Iran and gastric cancer is the deadliest kind of cancer. Following lung cancer, gastric cancer is the most common cancer in men. For women, the most common cancer is breast cancer. It is probable that diet, an environmental factor, plays an important role in the development of gastric cancer. 
The stomach stores food and combines it with digestive fluid to start digestion. There are many known risk factors for stomach cancer, but it is not known exactly how these factors cause cells of the stomach lining to become cancerous. Several changes thought to be pre-cancerous can occur in the stomach lining. In chronic atrophic gastritis, the normal glands of the stomach are either decreased or absent. There is also some degree of inflammation where the stomach cells are damaged by cells of the immune system. Atrophic gastritis is often caused by $H$. pylori infection. It can also be caused by an autoimmune reaction, in which a person's immune system attacks the cells lining the stomach. Some people with this condition go on to develop pernicious anemia or other stomach problems, including cancer. It is not known exactly how this condition might progress to cancer. Another possible pre-cancerous change is intestinal metaplasia. In this condition, the normal lining of the stomach is replaced with cells that closely resemble the cells that usually line the intestine. People with this condition usually have chronic atrophic gastritis as well. How and why this change occurs and progresses to stomach cancer is not well understood. This might also be related to a $H$. pylori infection [10].

Gastric is made of five layers which from the inside out, respectively, are as follows:

1- The innermost layer known as the lining, or mucosa. This is where most gastric cancers arise. Gastric acid and digestive liquid are secreted in this lining as well.

2- The next layer is the submucosa.

3- The stomach contents combines and mixes by movement of the muscle layer.

4- Two outer layers are connective tissues that surround the stomach.

Gastric cancer cells are often produced in the mucous layer and slowly spread to the other layers. Cancer changes begin in the mucosal lining and these early changes are rarely detectable. Stomach cancer released in several ways. It may spread into nearby organs from the lining or to nearby lymph nodes and cause them to be great and then propagate to whole body. By the development of gastric cancer, the cancer cells are deposited in organs such as the liver, lungs and bones through the blood circulation.

\section{Different Types of Cancer in the Stomach, Risk Factors and Prevention}

Originating in the cell lining of the stomach, adenocarcinoma is the most common type of cancer. Other types such as lymphoma, gastrointestinal stromal tumors and carcinoid tumors are less common. During the past few years, scientists have made much progress in understanding how certain changes in DNA can cause normal stomach cells to grow abnormally and form cancers. DNA is the chemical in each cell that carries our genes - the instructions for how our cells function. We resemble our parents because they are the source of our DNA. However, DNA affects more than how we look. Some genes help cells grow and divide into new cells. They are called oncogenes. Other genes that slow down cell division, cause cells to die at the right time, or help fix DNA damage are called tumor suppressor genes. Cancers can be caused by DNA changes that turn oncogenes on or turn tumor suppressor genes off.

Inherited mutations in some genes can increase a person's risk of stomach cancer. These are thought to cause only a small percentage of stomach cancers. However, genetic testing can still be done to look for the gene mutations that can cause some inherited cancer syndromes. Most of the gene changes that lead to stomach cancer occur after birth. Some of these changes might be caused by risk factors such as $H$. pylori infection or tobacco use. Other gene changes may just be random events that sometimes happen inside cells, without having an external cause [10].

Long-term infections by $H$. pylori bacteria may lead to inflammation and precancerous changes in the stomach lining. H. pylori is also associated with some types of gastric lymphoma. Other factors are gender (men more than women), age (risk increases after age 50), race (more common in Asians), diet (by eating smoked products, canned food, less vegetables and cereal and fresh fruit that contain neither vitamins A nor C), smoking, obesity, previous surgery on the stomach, malignant anemia, blood type $A$, a family history and some types of Stomach polyp. Antioxidants can destroy certain chemicals in the cells as free radicals. Free radicals can damage cell gene and cause cell death or cancer. Research is being performed on the effects of some nutrients with antioxidants such as vitamin $\mathrm{C}$, beta-carotene and vitamin $\mathrm{E}$. Their role to prevent gastric cancer is still unknown.

\section{Health Benefits of Eggplant skin}

Several study show that eggplant skin is rich in antioxidantcontaining compounds that cause resistance against premature aging in the body's cells. The iron, calcium and other minerals in eggplants supply the essential nutrients required by the body. Eggplants contain certain essential phyto nutrients which improve blood circulation and nourish the brain. These nutrients are concentrated in the skin of the eggplant. Incorporating eggplant into our diet can help reduce the harmful LDL cholesterol in our body. In fact, regular intake of eggplants can protect us with its high fiber, folate, potassium, manganese, vitamins $\mathrm{C}, \mathrm{K}$, and $\mathrm{B} 6$, phosphorus, 
copper, thiamin, niacin, magnesium, and pantothenic acid and from colon cancer. Studies indicate that eggplant skin has a number of health benefits due to all of these ingredients. well as traditional uses. The leaves and roots are traditionally used by juicing or boiling to make a tonic for throat and stomach troubles, asthma, skin diseases, rheumatism, inflammation, intestinal hemorrhages, foot pain, coughs, anorexia, toothache, or as a general stimulant. Another study found that Anthocyanin phytonutrients present in the skin of eggplants, called nasunin, are potent antioxidants that zaps free radicals and protects the lipids (fats) in brain cell membranes from damage [11].

\section{Methodology}

\section{Preparation of Alcoholic Extract of Eggplant Skin}

In order to prepare the alcoholic extract, 100 grams of eggplant skin with absolute ethanol were mixed and crushed by a laboratory apparatus. This mixture was placed in a water bath for 48 hours at $40^{\circ} \mathrm{C}$. Then, this mixture was passed through filter paper to separate the insoluble particles and coarse material (Fig.1, a \& b respectively). The alcohol remaining in the extract was removed by evaporation. At the end the dry matter was weighed by a digital scale and by the medium DMEM, the solution with concentrations $\mathrm{mg} / \mathrm{ml} 10,5,2.5,1.25,0.6,0.3,0.15,0.06,0.03$ and 0.01 were prepared. To sterilize, the extract obtained was passed through the syringe filter 0.22 micrometers.

\section{Preparation of Cancer Cells for Treatment with Alcoholic Ex- tract of Eggplant Skin}

Culture conditions vary widely for each cell type. For this experiment, the artificial environment in which the cells were cultured invariably consisted of a suitable vessel containing a substrate or medium that supplied the essential nutrients (amino acids, carbohydrates, vitamins, minerals), growth factors, hormones, and gases $\left(\mathrm{O}_{2}, \mathrm{CO}_{2}\right)$, and regulated the physicochemical milieu $(\mathrm{pH}$, osmotic pressure, temperature). Most cells are anchorage dependent and must be cultured while attached to a solid or semi-solid substrate (adherent or monolayer culture), while others can be grown floating in the culture medium (suspension culture) [12].

In this study, we used gastric cancer cells (AGS) to investigate apoptosis, and Fibroblasts cells (FIB) as a control group. Cell lines were obtained from the Iran Biological and Genetic Resources Center. The cells were cultured in DMEM containing 10\% inactivated fetal bovine serum (FBS), penicillin solution $(100 \mathrm{U} / \mathrm{ml}$ ) and streptomycin $(100 \mu \mathrm{g} / \mathrm{ml})$.

In order to study the cytotoxic effects of the alcoholic extract

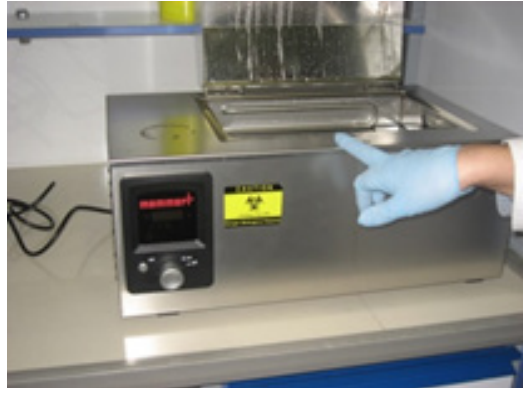

(A)

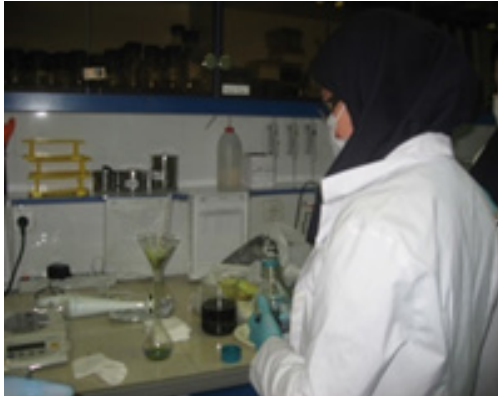

(B)

Figure 1: Procedures to prepare alcoholic extract of eggplant skin.

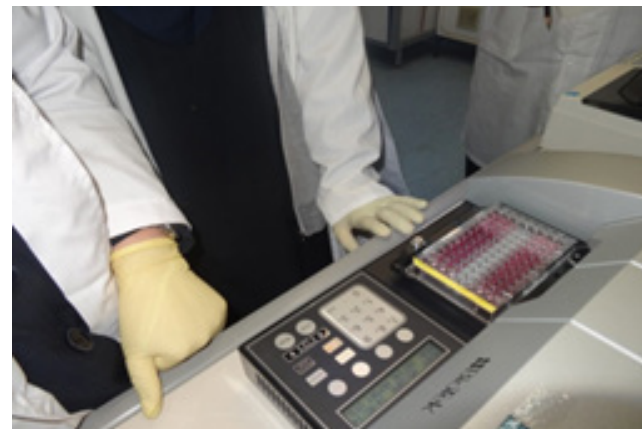

(C)

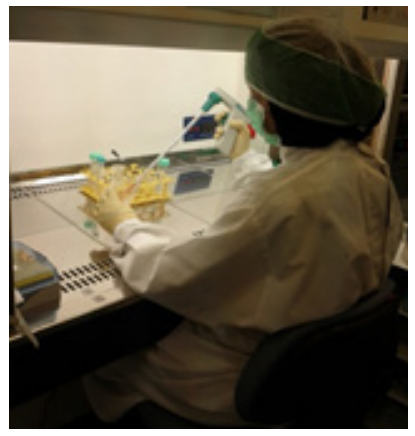

(D)

Figure 2: The cells with trypan blue were counted and cultured in plates. 

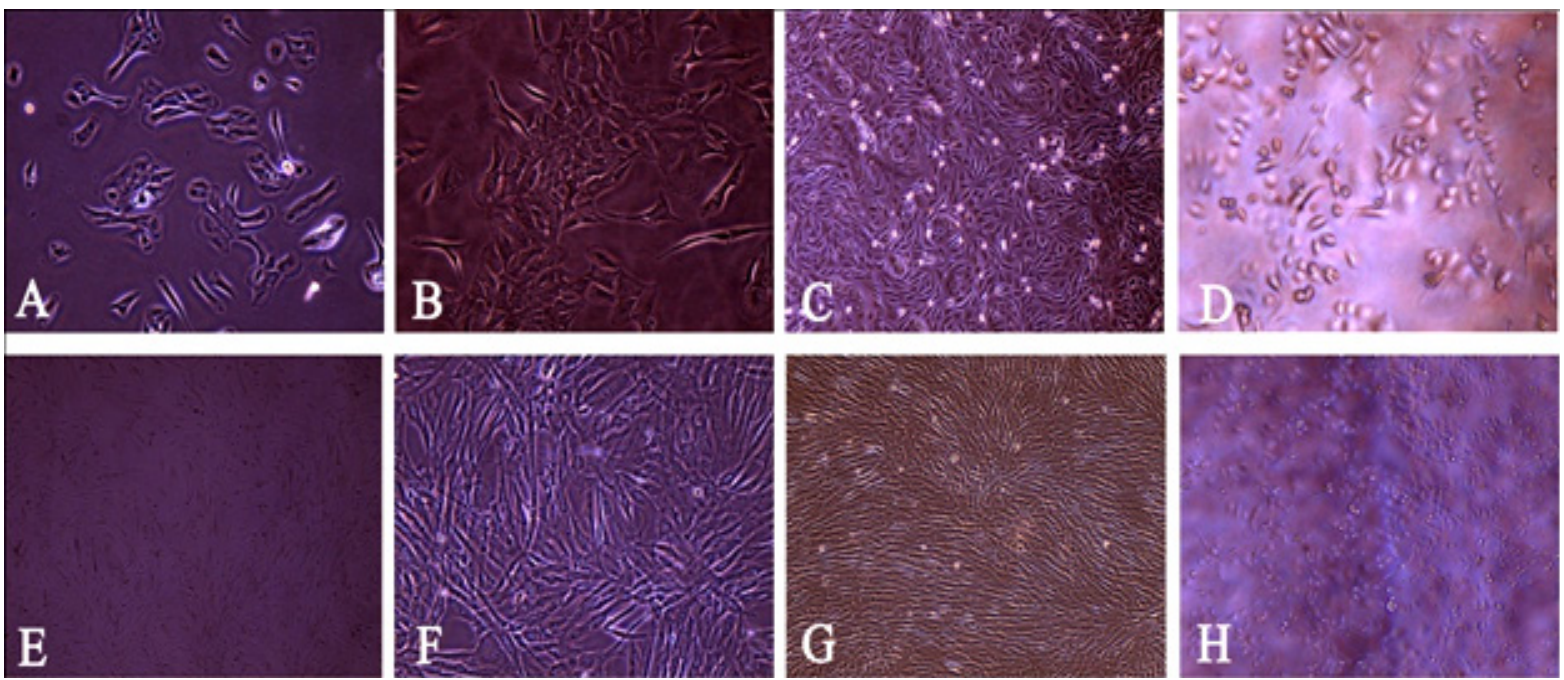

Figure 3: Cultured gastric cancer cells without adding extract (A-C), (D) the effect of extract on cancer cells, indicating cell death, (EG) the proliferation of normal cells without adding extract, $(H)$ Extract toxic effect on normal cells, (The magnification of cells are $100 \mathrm{X}$ ).

of eggplant skin cells on the AGS, the cells with trypan blue were counted and 104 cells were cultured in 96-well plates (Fig. 2), then were incubated overnight at $37^{\circ} \mathrm{C}$, with $5 \% \mathrm{CO}$ and 95 percent moist air to achieve adequate growth.

\section{Treatment and survival of cells}

After their preparation, the cells were treated with different concentrations of $20,10,5,2.5,1.25,0.625,0.312,0.156,0.078 \mu \mathrm{M}$ extracts of eggplant skin and it was repeated 3 times per concentration. The cytotoxic effects of eggplant skin were then investigated in 48 hours in an incubator. MTT method was used to evaluate the survival of cells in different concentrations and different time intervals. MTT is a yellow salt solution that mitochondria can revive it and by reducing it the insoluble purple formazan crystals are produced. The surface of culture medium was changed and new medium contain- ing $10 \mu \mathrm{L}$ of MTT solution was added. Then the cells incubated for 3 to 4 hours in a dark place to form insoluble formazan crystals. Then MTT was substituted by DMSO solution, crystals were dissolved with purple color. The greater the color intensity, the greater the number of living cells. Absorbance of the solution at $570 \mathrm{~nm}$ was measured.

\section{Results}

\section{Evaluation of Morphological Changes in Cells}

Morphology and health quality of the cells were assessed before adding the extract of eggplant skin. Before treatment, cells are without any granules around the nucleus and there are no changes in their main characteristics of adhesion or suspension. After the cells were treated with various concentrations of eggplant skin extracts, they were examined once again with a microscope (Fig. 3). The fol-

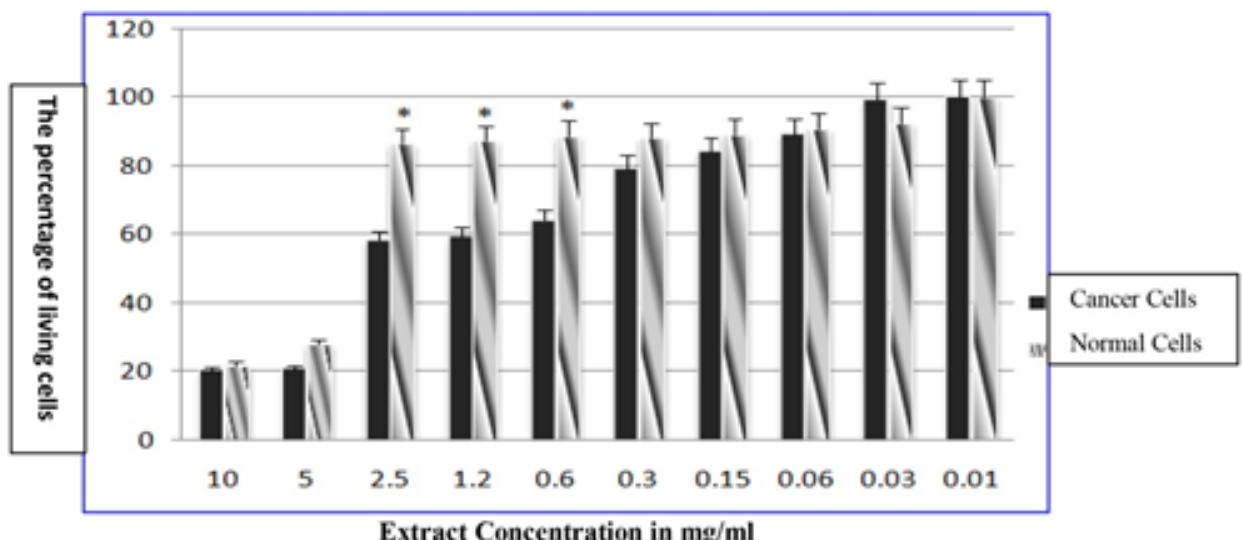

Figure 4: Cytotoxicity effect of alcoholic extract of eggplant skin on stomach cancer cells and normal cells. 


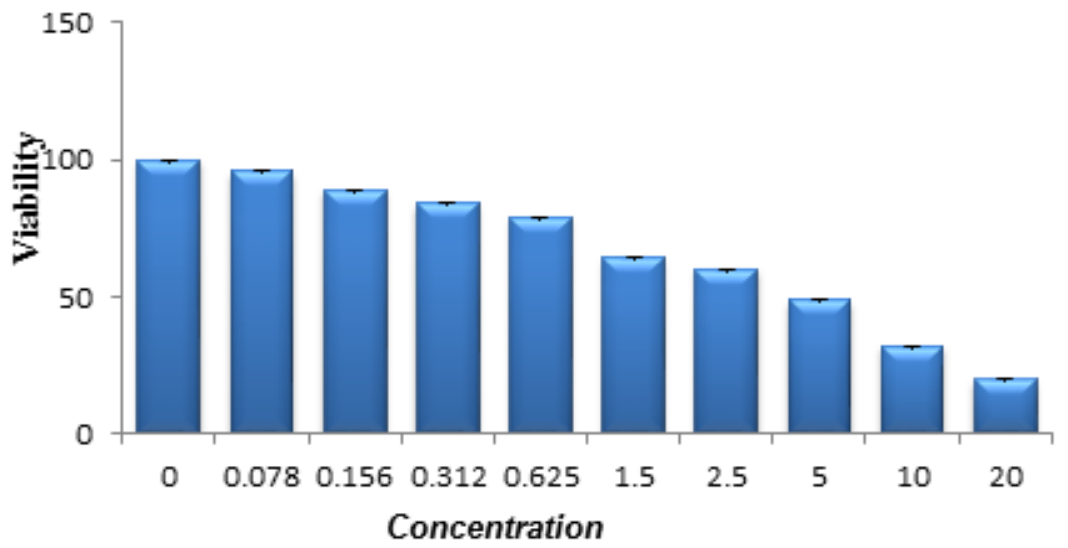

Figure 5: The effect of different concentrations in extract of eggplant skin on gastric cancer cells.

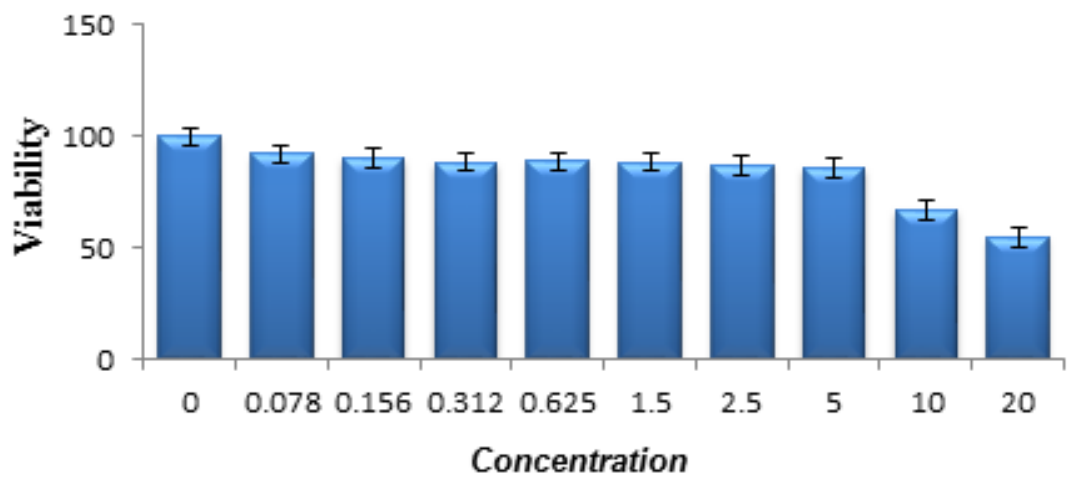

Figure 6: The effect of different concentrations in extract of eggplant skin on normal fibroblast cells.

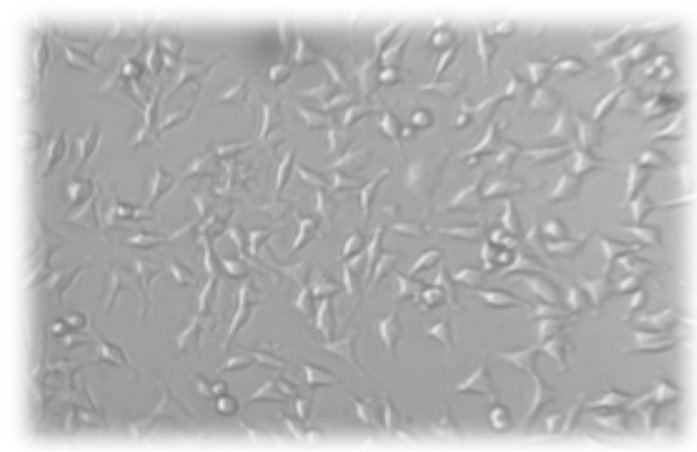

Figure 7: FIB normal cells after treatment with alcoholic extract of eggplant skin for 48h.

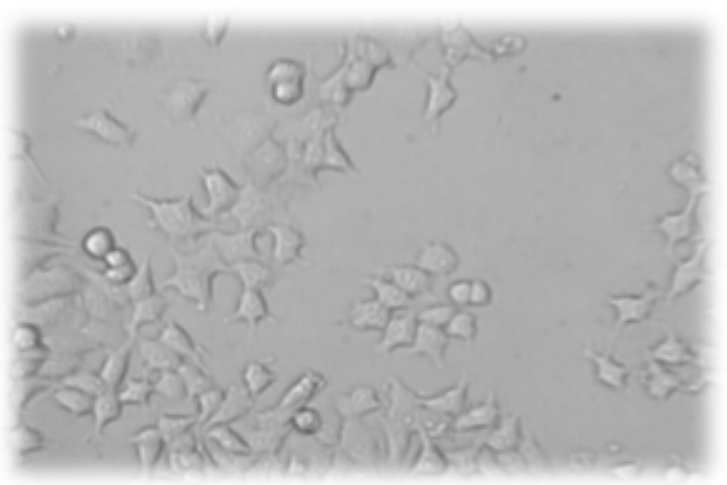

Figure 8: Induce apoptosis in AGS cancer cells after treatment with alcoholic extract of eggplant skin for 48h. 
lowing changes were observed in the cells:

- granules around the nucleus

- $\quad$ enlargement of the cells

- $\quad$ without adhesion and were suspended

These symptoms indicate that the cell viability decreased in presence of the extract and apoptosis increased.

\section{MTT Test}

The MTT test was done by treating the cells with concentrations of $10,5,2.5,1.25,0.6,0.3,0.15,0.06,0.03$ and $0.01 \mathrm{mg} / \mathrm{ml}$ during 48 hours. The IC50 (IC50 equal to 50\% concentration of the extract in which the cells remain alive) was reported 1.87 and $5.2 \mathrm{mg} / \mathrm{ml}$ for cancer and normal cells, respectively.

As shown in Figure (4), the viability of cancer cells in doses 0.6, 1.2 and $2.5 \mathrm{mg} / \mathrm{ml}$ of the extracts is less than normal cells. According to the results of MTT test and IC50 values, the toxic effect from the active substance of the eggplant extract is more on cancer cells compared to normal cells. It is interesting to note that the death rate of cancer cells at concentrations of 2.5, 1.25 and 0.75 relative to normal cells had a significant difference.

\section{Conclusion}

Figures 5 and 6 show the effect of different concentrations of eggplant skin extract $(20,10,5,2.5,1.25,0.625,0.312,0.156,0.078)$ on stomach cancer cell lines (AGS) and fibroblast normal cell line (FIB), respectively. As the figures show by increasing the concentration of eggplant skin, the cytotoxic effect is increased on gastric cancer cells but has no effect on normal cells. The results of this study showed that eggplant skin in concentrations of $2.5 \mathrm{mM}$ have a high cytotoxic effect on gastric cancer cell lines which could be due to the induction of apoptosis in these cells and in this concentration has the least effect on normal cells of fibroblasts.

\section{Acknowledgements}

We would like to thank the following people for their guidance and support throughout this project. Parvin Kashani as the manager of Rahe Shayestegan High School. The National Center for Genetic and Biological Resources of Iran; Dr. Farzaneh the chief of the centers cell bank and Dr. Meysam Gangi, Ahmad Nasimian and Masoomeh Asadi. We would like to thank Ariaian Young Innovative Minds (AYIMI) for supporting us in ICYS 2016 in winning the bronze medal and helping us produce this paper.

\section{References}

[1]-Kerr JF. History of the events leading to the formulation of the apoptosis concept. Toxicology, 2002;181-182:471-4.[PubMed]

[2]- Norbury CJ, Hickson ID. Cellular responses to DNA damage. Annu Rev Pharmacol Toxicol.2001;41:367-401.[PubMed]

[3]- Hirsch T, Marchetti P, Susin SA, Dallaporta B, Zamzami N, Marzo I, Geuskens M, Kroemer G. The apoptosis-necrosis paradox. Apoptogenic proteases activated after mitochondrial permeability transition determine the mode of cell death. Oncogene. 1997;15:1573-81. [PubMed]

[4]- Zeiss CJ. The apoptosis-necrosis continuum: insights from genetically altered mice. Vet Pathol.2003;40:481-95. [PubMed]

[5]- Kerr JF, Wyllie AH, Currie AR. Apoptosis: a basic biological phenomenon with wide-ranging implications in tissue kinetics. Br J Cancer. 1972;26:239-57. [PMC free article] [PubMed]

[6]- S. Elmore, "Apoptosis: A Review of Programmed Cell Death", NIEHS, Laboratory of Experimental Pathology, Research Triangle Park, North Carolina 27709, USA, Toxicol Pathol, 35(4): 495-516. 2007. https://www.ncbi.nlm.nih.gov/pmc/articles/PMC2117903/

[7]- Moheghi N, Afshari J T, Brook A. The Cytotoxic effect of Zingiber in Breast Afficinale in Breast Cancer (MCF7) Cell Line. Horizon Med Sci. 2011; 17(3):28-34, http://hms.gmu.ac.ir/article-1-1282-en.html

[8]- Shokrzadeh M., Parvaresh A. , Shahani S., Habibi E. , Zalzar Z.. Cytotoxic Effects of Lagenaria siceraria Standl. Extract on Cancer Cell Lin. J. of Mazandaran University of Medical Sciences.2013; 22 (97) :225-230.

[9]- http://patient.info/health/cancer-a-general-overview

[10]- http://www.cancer.org/cancer/stomachcancer/detailedguide/stomach-cancer-what-causes

[11]- http://foodfacts.mercola.com/eggplant.html

[12]- CELL CULTURE BASICS, www.invitrogen.com, handbook 


\section{REVIEW}

by Dr. Sarah Sabatinos, Assistant Professor, Department of Chemistry and Biology, Ryerson University

The authors present a test of eggplant skin effects on gastric cancer cell growth. Their choice of gastric cancer cells is made because it represents a high proportion of cancer diagnoses in Iran. They suggest that cells of the stomach are particularly affected by foods that we eat. The implication is that eggplant skin may kill gastric cancer cells.

They describe how eggplant is a beneficial food; additional citations of the studies that have shown this would be helpful. Given these common associations of eggplant with suspected health benefits, they alcohol-extract and dry the components of eggplant skin. They do not try to quantify the components of their extract, which would be difficult. They resuspend the dried extract in cell culture medium to test on two cell types: gastric cancer cells and normal fibroblasts.

The authors use the MT'T assay to show that cells are not proliferating and suggest that the mechanism is that cells are dying by apoptosis. MTT is a robust and well-characterized assay that measures cell metabolism related to both cell number and cell health. However, it does not necessarily show death or apoptosis. A complimentary assay in addition to the cell pictures would help to determine if their eggplant-skin reduction in MTT values are due to apoptosis in each concentration (see comments below). For the moment, their conclusions can state that there is less growth, and with the microscopy suggest that there is death that may be apoptotic.

This is an interesting study. There were a few edits to the text and some notes about data presentation. For example, I cannot see granules around the nucleus in Fig 3 (a close up would be good in future investigations). A scale bar would help to understand how much the cells enlarge (Fig3). While Figures 7 and 8 are very nice pictures, it would be wonderful if they could be compared with pre-extract at the same magnification and condition (and with a scale bar). Additionally, some work/ facts from the literature is presented but is without citations. I encourage the authors to build upon this paper and be proud of their idea and work. 